Claremont Colleges

Scholarship@ Claremont

All HMC Faculty Publications and Research

HMC Faculty Scholarship

1-14-2009

\title{
Thermal Links for the Implementation of an Optical Refrigerator
}

John Parker

David Mar

Steven Von der Porten

John Hankinson

Kevin Byram

See next page for additional authors

\section{Recommended Citation}

Parker, John, David Mar, Steven Von der Porten, John Hankinson, Kevin Byram, Chris Lee, Michael K. Mayeda, Richard Haskell, Qimin Yang, Scott Greenfield, and Richard Epstein. "Thermal links for the implementation of an optical refrigerator." Journal of Applied Physics 105.1 (2009): 013116-013116-11. DOI: 10.1063/1.3062522

This Article is brought to you for free and open access by the HMC Faculty Scholarship at Scholarship @ Claremont. It has been accepted for inclusion in All HMC Faculty Publications and Research by an authorized administrator of Scholarship @ Claremont. For more information, please contact scholarship@cuc.claremont.edu. 


\section{Authors}

John Parker, David Mar, Steven Von der Porten, John Hankinson, Kevin Byram, Chris Lee, Michael K. Mayeda, Richard C. Haskell, Qimin Yang, Scott R. Greenfield, and Richard I. Epstein 


\title{
Thermal links for the implementation of an optical refrigerator
}

\author{
John Parker, ${ }^{1, a)}$ David Mar, ${ }^{1}$ Steven Von der Porten, ${ }^{1}$ John Hankinson, ${ }^{1}$ Kevin Byram, ${ }^{1}$ \\ Chris Lee, ${ }^{1}$ Michael K. Mayeda, ${ }^{1}$ Richard Haskell, ${ }^{1}$ Qimin Yang, ${ }^{1}$ Scott Greenfield, ${ }^{2}$ \\ and Richard Epstein ${ }^{3}$ \\ ${ }^{1}$ Department of Engineering and Department of Physics, Harvey Mudd College, Claremont, \\ California 91711, USA \\ ${ }^{2}$ Chemistry Division, Los Alamos National Laboratory, MS J565 Los Alamos, New Mexico 87545, USA \\ ${ }^{3}$ International Space and Response Division, Los Alamos National Laboratory, MS B244 Los Alamos, \\ New Mexico 87545, USA
}

(Received 3 October 2008; accepted 20 November 2008; published online 14 January 2009)

\begin{abstract}
Optical refrigeration has been demonstrated by several groups of researchers, but the cooling elements have not been thermally linked to realistic heat loads in ways that achieve the desired temperatures. The ideal thermal link will have minimal surface area, provide complete optical isolation for the load, and possess high thermal conductivity. We have designed thermal links that minimize the absorption of fluoresced photons by the heat load using multiple mirrors and geometric shapes including a hemisphere, a kinked waveguide, and a tapered waveguide. While total link performance is dependent on additional factors, we have observed net transmission of photons with the tapered link as low as $0.04 \%$. Our optical tests have been performed with a surrogate source that operates at $625 \mathrm{~nm}$ and mimics the angular distribution of light emitted from the cooling element of the Los Alamos solid state optical refrigerator. We have confirmed the optical performance of our various link geometries with computer simulations using CODE V optical modeling software. In addition we have used the thermal modeling tool in COMSOL MULTIPHYSICS to investigate other heating factors that affect the thermal performance of the optical refrigerator. Assuming an ideal cooling element and a nonabsorptive dielectric trapping mirror, the three dominant heating factors are (1) absorption of fluoresced photons transmitted through the thermal link, (2) blackbody radiation from the surrounding environment, and (3) conductive heat transfer through mechanical supports. Modeling results show that a $1 \mathrm{~cm}^{3}$ load can be chilled to $107 \mathrm{~K}$ with a $100 \mathrm{~W}$ pump laser. We have used the simulated steady-state cooling temperatures of the heat load to compare link designs and system configurations. (C) 2009 American Institute of Physics.
\end{abstract}

[DOI: $10.1063 / 1.3062522]$

\section{INTRODUCTION}

Optical refrigerators remove heat from a specialized material with a laser beam through the process of anti-Stokes fluorescence. Several advantages are realized over other chiller technologies including small size, absence of vibrations, and no moving parts. ${ }^{1}$ In one version of the Los Alamos solid state optical refrigerator (LASSOR) system a nearinfrared laser $(\sim 1 \mu \mathrm{m}$ wavelength) is incident on a small $\sim 1 \mathrm{~cm}^{3}$ sample of ytterbium doped zirconium-bariumlanthanum-aluminum-sodium-lead fluoride glass $\left(\mathrm{ZBLANP}: \mathrm{Yb}^{3+}\right)$. The laser beam is confined within the glass by a set of dielectric trapping mirrors causing the beam to be absorbed largely by the ytterbium ions. The absorption of this laser light causes the glass to re-emit higher energy photons, via anti-Stokes fluorescence, resulting in a net energy loss and cooling of the glass.

The technology has advanced rapidly since 1995 when the LASSOR team reported the first cooling results due to anti-Stokes fluorescence of ZBLANP: $\mathrm{Yb}^{3+}{ }^{2}$ By 1999 researchers demonstrated a cooling drop of $65^{\circ} \mathrm{C}$ using ZBLAN: $\mathrm{Yb}^{3+}{ }^{3,4}$ The LASSOR system holds the record for optical cooling, reaching $208 \mathrm{~K}$ in 2005 using an improved

${ }^{a)}$ Electronic mail: jjsparker@gmail.com.
ZBLANP system and a higher power laser. ${ }^{5}$ In the past decade, ZBLAN and ZBLANP have become the most common materials for optical refrigeration research with current work seeking to reduce impurities in the glass. ${ }^{6,7}$ To enhance the cooling efficiency, research has been underway to improve cavity absorption using retroreflectors and a secondary cavity and to extract the maximum anti-Stokes fluorescence radiation from the cavity. ${ }^{8-12}$ Laser cooling has been reported for a variety of other materials including those doped with $\mathrm{Yb}^{3+}$ [fluorochloride glass (CNBZn), ${ }^{13}$ fluoride glass (BIG) ${ }^{13}$ $\mathrm{KGd}\left(\mathrm{WO}_{4}\right)_{2},{ }^{14} \mathrm{KY}\left(\mathrm{WO}_{4}\right)_{2},{ }^{15}$ yttrium aluminum garnet (YAG), ${ }^{16} \mathrm{Y}_{2} \mathrm{SiO}_{5},{ }^{17} \mathrm{KPb}_{2} \mathrm{Cl}_{5},{ }^{17}$ and $\mathrm{BaY}_{2} \mathrm{~F}_{8}$ (Refs. 18 and 19)], those doped with $\mathrm{Tm}^{3+}$ [ZBLANP ${ }^{20,21}$ and $\mathrm{BaY}_{2} \mathrm{~F}_{8}$ (Ref. 22)], and those doped with $\mathrm{Er}^{3+}$ [CNBZn (Ref. 23) and $\mathrm{KPb}_{2} \mathrm{Cl}_{5}$ (Ref. 23)]. Another new research area of great interest is the cooling of GaAs optoelectronics using semiconductor materials that can theoretically reach temperatures as low $10 \mathrm{~K}$; however, several problems including extraction of the fluorescent radiation have prevented any net cooling from being realized. ${ }^{24-28}$

All practical laser refrigerators inevitably involve the attachment of heat loads. In this paper, we present thermal link designs for the attachment of heat loads that minimize the loss of cooling power due to poor thermal conductivity and 
due to absorption by the load of thermal radiation and fluorescence photons. The latter is due to dielectric mirror leakage, which was recognized by Mills et al. $^{29}$ in 2002 as the major contributor to the loss of cooling power. Optical refrigeration using proprietary thermal links to attached heat loads has been reported by Mills et al., ${ }^{30,31}$ and a cooling drop of $7.9^{\circ} \mathrm{C}$ was demonstrated using a load equivalent in size to a small sensor.

\section{A. Laser cooling physics}

An explanation of the cooling process is necessary to understand the source of the leaked photons. To cool ZBLANP glass, the pump laser excites a $\mathrm{Yb}^{3+}$ dopant ion from a high energy level of the ground manifold to a low energy level of the next higher manifold. ${ }^{32}$ The ion absorbs a phonon and transitions to a higher level in this upper manifold. It subsequently relaxes to a random level in the ground manifold and releases a fluoresced photon with more energy than the absorbed photon. ${ }^{33}$ Because the energy difference is orders of magnitude smaller than the photon energy, the average energy liberated from the system per excitationrelaxation cycle is much smaller than the energy of the photons involved. As a result, it is crucial to understand where the fluoresced photons go after their emission because any absorption of the high-energy fluorescence by the heat load greatly diminishes the net cooling effect of the process. In 2002, Mills et al. ${ }^{34}$ reported that the angle-dependent reflectivity inherent to all dielectric trapping mirrors allows considerable photon leakage at high angles of incidence preventing the direct attachment of heat loads to the cooling element. To avoid this problem, an optical refrigerator can utilize a thermal link that transmits heat between the load and the cooling element while preventing fluorescent radiation from heating the load.

\section{B. Basic model of an optical refrigerator with thermal link}

The basic model for a thermal link is simple. We assume that fluorescence photons originate uniformly throughout the $1 \mathrm{~cm}^{3}$ cooling element and are emitted isotropically. To prevent undesirable heating, these photons must be transmitted to the outer chamber walls where their absorption does not affect the cooling process. We refer to these absorptive walls as "baffling" to avoid confusion with other interfaces. A vacuum separates the cooling element from the baffling to prevent convective heat transfer.

The cooling efficiency of the optical refrigeration system is typically below 1\%; consequently, the average power of the light fluoresced from the ZBLANP glass is two orders of magnitude greater than the average power removed from the system in the cooling process. The transfer of this refrigeration effect to a useful thermal load, such as a small infrared detector, can be nullified by relatively few leaked photons. When the high-energy fluoresced photons are absorbed anywhere other than the baffling, heating occurs and the cooling effect is reduced. A well-designed optical refrigerator must

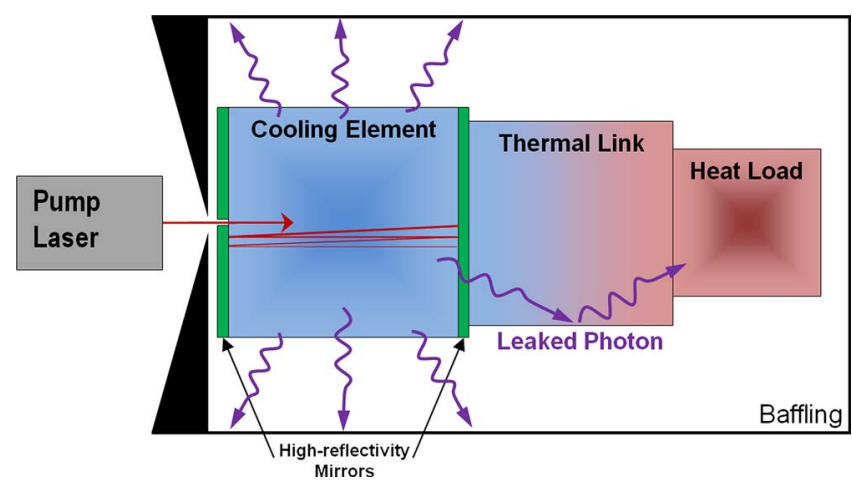

FIG. 1. (Color online) Optical schematic of the simplest link design using a block of transparent material. The large arrow on the left shows the pump laser light incident on the cooling element. The arrow passing through the trapping mirror and into the thermal link illustrates a leaked light ray that would reflect through the link.

also limit other sources of heating including conduction from the support fibers and black-body radiation from the baffling. 35,36

\section{FOUR THERMAL LINK DESIGNS}

The dielectric trapping mirrors on the cooling element greatly reduce the near-normal-incidence light transmitted toward the heat load but allow high leakage of off-normal rays (see Fig. 1). As a consequence, link designs must prevent these off-normal rays from reaching the potentially absorptive heat load region.

As Fig. 1 suggests, if poor link geometry is chosen, fluoresced photons will be guided via total internal reflection through the link to the load. We have employed four different geometries in our link designs to minimize the transmission of photons to the load. The designs aim to capture photons leaked through the dielectric mirror at angles of incidence $>30^{\circ}$ and prevent them from heating the load. Light transmission through the link-vacuum interface onto the baffling can be increased in three ways: (1) applying antireflective coatings to all vacuum interfaces, (2) employing square link cross sections to minimize lateral modes, and (3) using a link material with a low index of refraction to increase the critical angle for total internal reflection. The surface area of the thermal link must be minimized to reduce heat absorption from the blackbody radiation of the baffling, but the crosssectional area of the link must be large enough to provide good conductive heat transfer between the thermal load and the cooling element. These two factors do not dominate heat flow near room temperature but have a greater effect as the temperature drops (see Secs. V and VI).

\section{A. Design 1: Multiple mirrors}

The first solution employs multiple highly reflective coatings in the space between the cooling element and the thermal load in order to reflect light outward onto the baffling. The design employs dielectric mirrors, which are assumed to have essentially no absorption, and a high reflectivity envelope over a narrow band of angles. By using multiple mirrors tuned to reflect different angles of inci- 


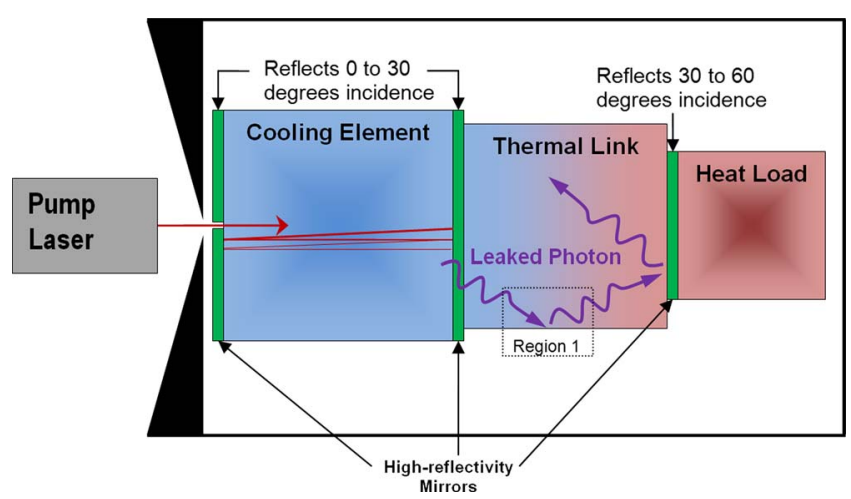

FIG. 2. (Color online) The multiple cascaded mirrors link. The mirrors on the cooling element have the greatest reflectivity around normal incidence. As the light propagates toward the load, the additional mirrors have peak reflectivity at increasing angles of incidence.

dence, the design prevents light from reaching the load. Figure 2 shows the simplest case using only two mirrors.

Assuming the trapping mirrors of the $1 \mathrm{~cm}^{3}$ cooling element have high reflectivity in a $0^{\circ}-30^{\circ}$ envelope of incidence angles, we can ensure that no light rays have a direct path from the fluorescing face of the cooling element to the absorptive thermal load by separating them by at least 3.5 $\mathrm{cm}$. As a result, the second mirror is responsible only for $>30^{\circ}$ off-normal rays that have been reflected at the linkvacuum interface. For example, a second mirror tuned to reflect light incident from $30^{\circ}$ to $60^{\circ}$ blocks those leaked rays being guided down the link as shown in Fig. 3. The steeper rays from $60^{\circ}$ to $90^{\circ}$ are transmitted out of the link to the baffling because they are below the critical angle on the lateral faces.

Figure 3 shows a magnified view of the thermal linkvacuum interface at the bottom of the link in Fig. 2. Figure 3 accounts for the distinct ranges of angular incidence on the link-vacuum interface. Region A shows angles of incidence on the interface greater than $60^{\circ}$, which theoretically should be of negligible intensity if the first dielectric mirror reflects all incident rays with angles less than $30^{\circ}$. Region $\mathrm{C}$ shows rays incident below the critical angle that will partially transmit through the interface to the baffling. Finally, region B shows the angles that will have been passed by the first mirror and fall within the total internal reflection envelope on

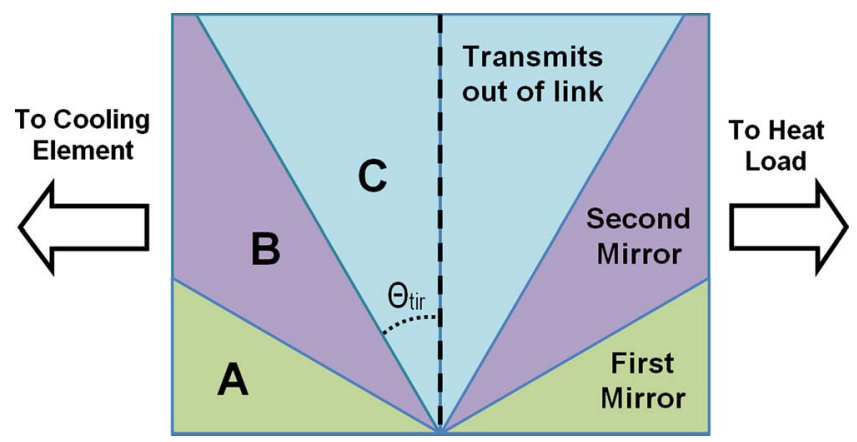

FIG. 3. (Color online) A magnified view of the thermal-link-to-vacuum interface (region 1 in Fig. 2). Region A is dark given that the first dielectric mirror has high reflectance from $0^{\circ}$ to $30^{\circ}$ angles of incidence. Region $\mathrm{B}$ shows the rays that will be reflected by the second mirror. Region $\mathrm{C}$ shows the range of angles that are transmitted out of the link to the baffling.

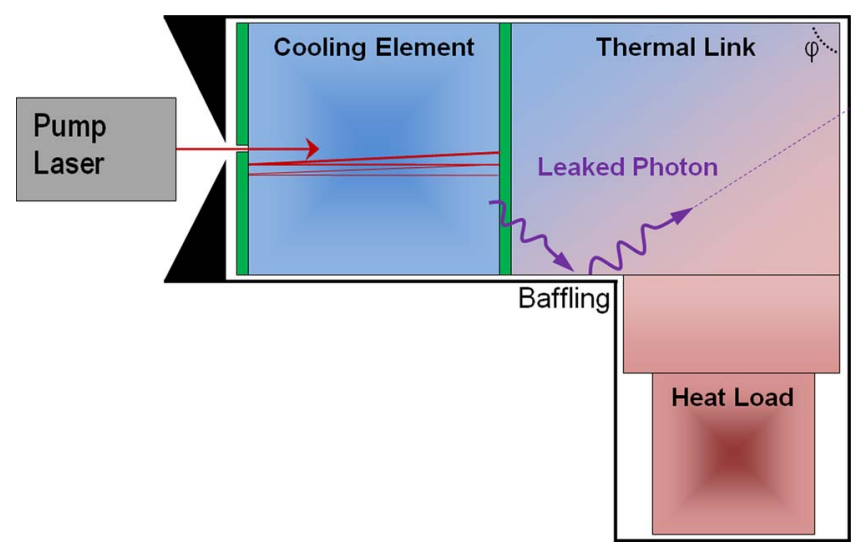

FIG. 4. (Color online) The kinked waveguide link. The high angle kink allows light to leave the thermal link before reaching the load. The arrows within the link represent leaked light rays transmitted through the right-hand face of the cooling element. The corner angle $\varphi$ is adjusted in order to optimize the design.

the lateral interface of the link. It is the light rays in region B and high angles in $\mathrm{C}$ that the second mirror is intended to shield from the thermal load.

One disadvantage of the "multiple mirrors" design is that the multiple reflective surfaces can potentially lead to trapped rays. Despite very low absorption levels in the link or mirror coatings, this situation could potentially generate heat that nullifies the cooling process.

\section{B. Design 2: Kinked waveguide}

This design utilizes a kinked waveguide structure for the thermal link that places the load off axis from the cooling element and allows light to leak out of the link to the baffling before reaching the load. In a step-index waveguide, light propagates through a series of shallow reflections off the sides. The kink in our waveguide causes light, which hits the sides at shallow angles in the first half of the link, to be incident at near-normal angles to the sides of the second half of the link (see Fig. 4). This allows light that was propagating through the waveguide to exit the link material and be absorbed by the baffling. The corner angle $\varphi$ is varied based on the angular distribution of light entering the link. If mul-

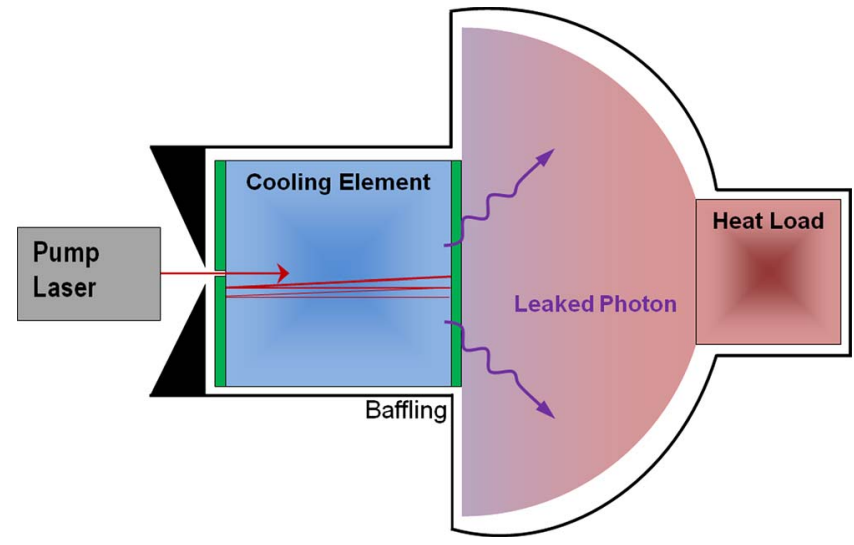

FIG. 5. (Color online) The hemisphere link. The design allows all rays to pass through the link-vacuum interface with minimal reflection by keeping the angles of incidence below the critical angle. 


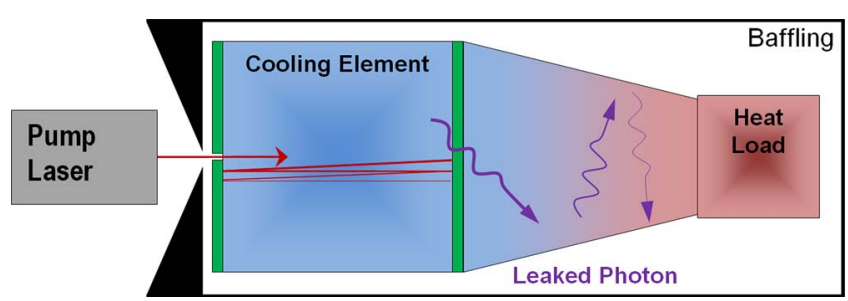

FIG. 6. (Color online) The taper link. The cross-sectional area of the pyramidal link gradually decreases toward the load. Light rays are shown leaking through the trapping mirror and propagating down the link. The transmission of light to the baffling increases as light rays reflect off the linkvacuum interfaces due to the decreasing angles of incidence at successive bounces.

tiple kinks are cascaded in such a way that each kink has a corner angle tuned to a different angular distributions of light, the total transmission of light through the link will further decrease.

\section{Design 3: Hemisphere}

The hemispherical design, which was first demonstrated by Gauck et al. ${ }^{37}$ (see Fig. 5), creates a link-vacuum interface that presents near-normal incidence at all points to fluorescence photons. This is achieved by making a hemisphere with a radius larger than the size of the emitting face. In the limit as the hemisphere grows, the cooling element effectively becomes a point source and the isotropically emitted photons are incident close to normal on the link-vacuum interface. Reflections are minimal and photons are delivered to the surrounding baffling. To minimize link size, the emitted photons are only required to have an angle of incidence less than the critical angle, and as a result the minimum radius of the hemisphere is dependent on the refractive index. This is described by Eq. (1) for a $1 \times 1 \mathrm{~cm}^{2}$ emission face with trapping mirrors that are highly reflective up to $30^{\circ}$,

$$
r_{\min }=\frac{n_{1} \sqrt{6}}{4} \mathrm{~cm} \approx 0.61 \mathrm{~cm} \times n_{1} .
$$

\section{Design 4: Taper}

This design uses pyramidal link geometry to decrease the angle of incidence at the link-vacuum boundary after each internal reflection, taking full advantage of the angular distribution of leaked rays through the dielectric trapping mirrors. As previously discussed, the dielectric mirror on the cooling element leaks almost no light at angles of incidence less than $30^{\circ}$, filtering the angular distribution of light entering the taper. As shown in Fig. 6, the remaining light will undergo a series of internal reflections at the link-vacuum interface. Due to the tapered shape each reflection shifts the direction of light propagation until the light is transmitted through the sides at near-normal incidence and is absorbed by the baffling. By the end of the link, the reflected light has become heavily attenuated and the minimal light remaining reverses direction and heads back toward the cooling element. The length and angle of the taper are adjusted depending on expected mirror leakage and size requirements of the cooling element and heat load.

\section{OPTICAL TESTS OF THE LINKS}

To test the optical performance of our thermal link designs, we constructed a light source that mimics the ZBLANP fluorescent cube employed in the LASSOR system but avoids the use of expensive components such as (1) the specialized doped ZBLANP cooling element, (2) the highpower infrared laser required to induce cooling in a solid, and (3) a complex vacuum chamber setup. With the surrogate system, we performed measurements of light intensity at the location of an absorptive heat load and calculated the amount of heating that would result from the absorption of those incident photons. The optical design of this thermal link can be translated into the appropriate wavelengths and indices of refraction employed in the actual LASSOR cooling system by changing material and coating properties. Sections III A and III F describe the creation of an angular light distribution emitted by a $1 \times 1 \mathrm{~cm}^{2}$ face that closely resembles the light distribution present in the LASSOR setup. In Sec. III G we present the results of optical tests of the links performed with this surrogate system.

\section{A. Creation of a wide angular distribution of light}

The surrogate source system must mimic the angular light distribution resulting from the isotropic fluorescence in the $1 \mathrm{~cm}^{3}$ cooling element. Several designs were considered, but the most effective surrogate source design employed light scattered from titanium dioxide nanoparticles suspended in toluene inside a type 2 cuvette. The reasons for choosing this design were (1) to generate isotropically emitted light by scattering photons in all directions within the cuvette, (2) to provide a refractive index close to that of ZBLANP, (3) to provide a uniform refractive index within the surrogate source to avoid extraneous reflections, and (4) to produce a wide angular distribution of light at the outer faces. The use of a scattering solution provided adjustment of the scattering levels, and the use of a glass cuvette provided an ideal surface on which to attach the link designs. A microscope coverslip was coated with dielectric layers to yield a high-reflectance mirror (Cascade Optical Corp., Santa Ana, $\mathrm{CA}$ ), and the coverslip/mirror was attached to the emission end of the cuvette with index-matching fluid. The dielectric mirror was designed to closely match the LASSOR system having high reflectance at near-normal incidence and high transmission at off-normal incidence.

\section{B. Suspension agent and cuvette}

The small refractive index change between the toluene $(n=1.49)$ and the cuvette glass $(n=1.52)$ ensured that the wide angular distribution created in the cuvette would not be reduced by refraction. Titanium dioxide nanoparticles have a large refractive index $(n=2.4)$, which makes them highly effective at scattering light when placed in the lower index toluene medium.

The interior cross section of the cuvette had the same dimensions as the LASSOR cooling element: $1.0 \times 1.0 \mathrm{~cm}^{2}$. Housing the scattering solution within a cuvette resulted in a $1 \mathrm{~mm}$ glass separation between the scattering solution and the first dielectric mirror surface. This is qualitatively differ- 


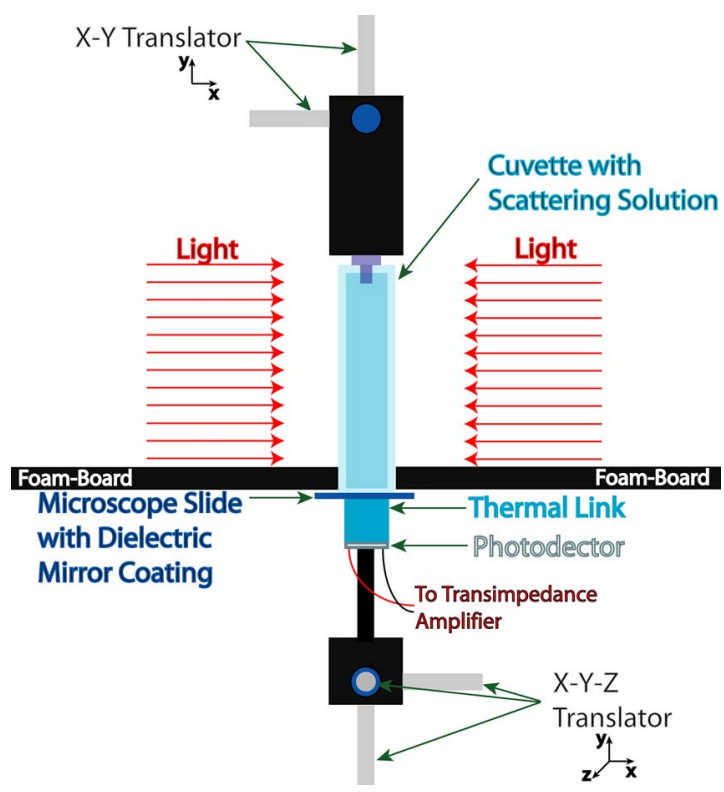

FIG. 7. (Color online) Surrogate source setup (top view). The cuvette contains titanium dioxide nanoparticles in a solvent of toluene. Four $627 \mathrm{~nm}$ LEDs illuminate the cuvette and the light scattered by the nanoparticles serves as a surrogate light source. A microscope coverslip with a dielectric mirror coating in optical contact with the bottom-face of the cuvette mimics the trapping mirror in the LASSOR setup. A large area photodetector records the light transmitted by the thermal link and the optical power emitted from the cuvette end-face as well as transmitted by the dielectric mirror.

ent from the LASSOR setup in which the high reflectivity coating is applied directly to the face of the glass cooling element. Two additional problems associated with using a scattering solution in a cuvette were the possibility of trapped air bubbles and the awkward elongated axis of the cuvette. Despite these challenges, the cuvette system yielded the desired angular distribution of emitted light. The angular distribution of light at the emission face was measured using a photodetector mounted on a radial arm, while a hemisphere was optically coupled to the emission face of the cuvette to minimize refraction. The measured results agreed with the expected values for the angular distribution of light from the LASSOR cooling element.

\section{Surrogate source setup}

Figure 7 shows the two sets of translation stages used to adjust the position of the cuvette and the photodetector. The cuvette was pumped with light emitting diodes (LEDs), and the position of the cuvette within the illuminated region was held constant while various link designs were tested. Black foam board was used as highly absorptive baffling to optically isolate the mirror, thermal link, and photodetector from the light incident upon the cuvette as well as light scattered from other faces.

In order to obtain higher detector sensitivity we used a lock-in amplifier system, which filtered out the noise and isolated the signal, thereby increasing the signal-to-noise ratio. The modulated driving signal for the LEDs was generated at $100 \mathrm{~Hz}$ to filter-out room lights and was amplified using a Darlington pair current driver. A large active area $\left(94 \mathrm{~mm}^{2}\right)$ silicon photodiode was used to capture the trans- mitted light through the system. The photodiode was optically coupled to the link to reduce reflections at the interface. The detector's area was equal to that of the expected heat load. Thus the detector output provided a good measure of the total optical power expected to be absorbed at the load.

\section{Pump light source}

The surrogate system required a light source that provided sufficient power given the sensitivity of the photodetector, but power low enough to avoid safety hazards. We used visible wavelength LEDs for pump illumination and in order to gain immediate visual feedback on the functionality of the link. LEDs provided powerful diffuse illumination at a relatively low cost with a wide variety of visible wavelengths. The surrogate source was pumped with four $627 \mathrm{~nm}$ Luxeon III star LEDs with a spectral full width at half maximum of $\sim 25 \mathrm{~nm}$ (measured with a grating spectrometer), and a maximum of $210 \mathrm{~mW}$ optical power for each LED. ${ }^{38}$ The ratio of the spectral width to center wavelength of the LEDs was similar to that of the $\mathrm{Yb}^{3+}$ fluorescence spectrum.

\section{E. Dielectric mirrors}

Dielectric mirrors were a key component in all of the design solutions. The coated microscope coverslips were ideal for this application given their high reflectivity and low absorption. The ZBLANP cooling element in the LASSOR setup is coated on two opposing faces with dielectric mirrors as a trapping mechanism for the pump laser. The two key characteristics of the coverslip mirrors are their minimal thickness and their refractive index match to the cuvette glass. This allowed us to place the thin mirror against other components in our system using index-matching fluids to reduce interface effects and therefore emulate a coating applied directly. We used No. 1 coverslips with $0.13-0.17 \mathrm{~mm}$ thickness. We verified the reflection and transmission coefficients of the dielectric mirrors using a $\mathrm{He}-\mathrm{Ne}$ laser, with the mirror under test optically coupled between two acrylic hemispheres. We measured the mean mirror reflection coefficient to be $>0.99$ from $0^{\circ}$ to $40^{\circ}$, which provided a $10^{\circ}$ margin on our design estimates, which assumed mirror leakage at angles greater than $30^{\circ}$.

\section{F. Measurements of the angular distribution of emitted light}

The angular distribution provided by the surrogate source was measured using a pivoting arm with the axis of rotation running through the center of and lying in the plane of the emission face of the cuvette. The photodetector was mounted on the mobile end of the arm facing the emission face. An acrylic hemisphere was placed over the emission face and optically coupled to it with index-matching fluid to allow the light to pass through the acrylic-air interface with minimal refractive effects.

The repeatability of our link transmission results depends on the reproducibility of our angular distribution. The effectiveness of our designs is strongly dependent on the angles of light that enter them after leaking through the dielectric mirror. The cuvette emits a large portion of the light 


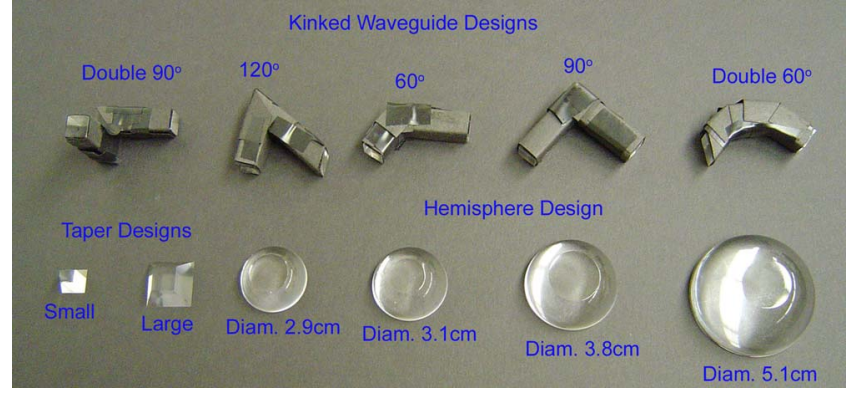

FIG. 8. (Color online) The photo shows many of the link designs that were fabricated and tested. Each design was created from a single piece of acrylic.

distribution in the $50^{\circ}-60^{\circ}$ leakage angles; however very little light is emitted in the $65^{\circ}-75^{\circ}$ range. Based on our calculations and computer modeling, we determined that the surrogate source's angular distribution is a good representation of the LASSOR system, yet the subtle effects of secondary photon absorption and internal reflections within the cooling element could cause deviations in the dominant leakage angles.

\section{G. Results of the optical tests of the thermal links}

The designs tested are shown in Fig. 8. Each link was constructed from a single piece of acrylic. Transmission coefficients were measured using the lock-in amplifier system and are listed in Table I. The two columns of the data represent transmission coefficients with respect to the cuvette face (before the glass slide with the dielectric mirror) and after the dielectric mirror. All of the link designs reduced photon transmission to the thermal load. The most effective link tested was the thin $120^{\circ}$ kinked waveguide with a crosssectional area of $25 \mathrm{~mm}^{2}$. Smaller link cross sections and longer lengths would further reduce the transmission of light but would also reduce the rate of heat transfer. Among the links that couple to the entire emission face of the cuvette, the most effective one was the small taper with a net transmission from the cuvette of $0.04 \%$. Because mirror coatings can be used to improve the other link systems without increasing the adverse heating factors, we do not report on the stand-alone performance of the multiple mirrors design (design 1).

As shown in Table I, the transmission decreased as the size of the hemispheres increased, as the angle of the kink increased, and as the angle of the taper increased-all as expected from theory (see Sec. IV). The trade-offs between these designs depend on the link volume, the surface area, and the space required inside the LASSOR vacuum chamber. The effects of these trade-offs on the final load temperature are discussed in Secs. V and VI. In addition to these transmission coefficients, results were measured for compound designs achieved by combining multiple systems in series. While lower transmission designs were created using such an approach, they are not included here as their sizes became too large to be practical. Future designs to consider might include integrated compound links, which use less material by merging several designs into one piece of acrylic, such as
TABLE I. Link transmission results: $\mathrm{KW}=$ kinked waveguide, $\mathrm{H}=$ hemisphere, and $\mathrm{T}=$ taper.

\begin{tabular}{lcc}
\hline \hline Link & $\begin{array}{c}\text { Transmission from cuvette } \\
(\%)\end{array}$ & $\begin{array}{c}\text { Transmission from mirror } \\
(\%)\end{array}$ \\
\hline Thin $120^{\circ} \mathrm{KW}$ & $0.012 \pm 0.003$ & $0.15 \pm 0.03$ \\
Small T & $0.041 \pm 0.008$ & $0.50 \pm 0.07$ \\
$\mathrm{H}$ diameter $5.1 \mathrm{~cm}$ & $0.049 \pm 0.009$ & $0.61 \pm 0.08$ \\
Double $120^{\circ} \mathrm{KW}$ & $0.07 \pm 0.01$ & $0.88 \pm 0.09$ \\
$\mathrm{H}$ diameter $3.8 \mathrm{~cm}$ & $0.074 \pm 0.006$ & $0.92 \pm 0.03$ \\
$\mathrm{H}$ diameter $3.1 \mathrm{~cm}$ & $0.096 \pm 0.007$ & $1.19 \pm 0.03$ \\
$120^{\circ} \mathrm{KW}$ & $0.11 \pm 0.02$ & $1.4 \pm 0.2$ \\
$\mathrm{H}$ diameter $2.9 \mathrm{~cm}$ & $0.13 \pm 0.01$ & $1.57 \pm 0.05$ \\
Double $90^{\circ} \mathrm{KW}$ & $0.32 \pm 0.06$ & $3.9 \pm 0.5$ \\
Large T & $0.62 \pm 0.05$ & $7.7 \pm 0.3$ \\
$90^{\circ} \mathrm{KW}$ & $1.2 \pm 0.2$ & $15 \pm 2$ \\
Double $60^{\circ} \mathrm{KW}$ & $1.4 \pm 0.2$ & $17 \pm 2$ \\
$60^{\circ} \mathrm{KW}$ & $1.9 \pm 0.3$ & $23 \pm 3$ \\
Mirror alone & $8.1 \pm 0.4$ & 100 \\
\hline \hline
\end{tabular}

a kinked waveguide with a tapered end. Additional mirrors added before the load and tuned to off-normal incidence would further enhance the link performance.

While the links we tested were made from acrylic, sapphire is the link material favored for optical refrigerators as it has a high thermal conductivity, a high transparency in the near IR, and it is well suited for vacuum chamber use. The higher refractive index of sapphire will require a small increase in size due to a lower critical angle and more total internally reflected light.

\section{COMPARISON WITH OPTICAL SIMULATIONS OF THE LINKS}

CODE V optical design software from Optical Research Associates (Pasadena, CA) was used to model the optical performance of the link designs. The software calculates the behavior of light in an optical system by tracing the paths of a large quantity of discrete rays as they move from surface to surface in the system model. The properties of the rays are altered at each surface, including the effects of Fresnel reflection and transmission. Our four designs were modeled as collections of nonsequential surfaces, and transmission was analyzed by comparing the optical power exiting the system to the optical power entering the system.

In conformance with the operational requirements of a nonsequential range in CODE $\mathrm{V}$, each model consisted of the object (light source), one entrance surface, one exit surface, and the image (where the output intensity is measured). The link design was expressed as a nonsequential range of sur-

TABLE II. Computer modeling results: $\mathrm{KW}=$ kinked waveguide, $\mathrm{H}=$ hemisphere, and $\mathrm{T}=$ taper.

\begin{tabular}{lcc}
\hline \hline Link & $\begin{array}{c}\text { Measured transmission } \\
(\%)\end{array}$ & $\begin{array}{c}\text { Computed transmission } \\
(\%)\end{array}$ \\
\hline Mirror alone & 8.1 & 13 \\
H diameter $2.9 \mathrm{~cm}$ & 0.12 & 0.35 \\
H diameter $5.1 \mathrm{~cm}$ & 0.049 & 0.13 \\
Small T & 0.040 & 0.033 \\
\hline
\end{tabular}


TABLE III. The dimensions of the different link designs that were used in the thermal modeling are listed below: $\mathrm{KW}=$ kinked waveguide, $\mathrm{H}=$ hemisphere, and $\mathrm{T}=$ taper.

\begin{tabular}{lccc}
\hline \hline Design name & Dimension 1 & Dimension 2 & Dimension 3 \\
\hline $\mathrm{H}$ diameter $2.9 \mathrm{~cm}$ & Diameter $2.9 \mathrm{~cm}$ & End face diameter $1.41 \mathrm{~cm}$ & \\
$\mathrm{H}$ diameter $3.1 \mathrm{~cm}$ & $\begin{array}{l}\text { Diameter } 3.1 \mathrm{~cm} \\
\text { End face diameter } 1.41 \mathrm{~cm}\end{array}$ & End face diameter $1.41 \mathrm{~cm}$ & \\
$\mathrm{H}$ diameter $3.8 \mathrm{~cm}$ & Diameter $3.8 \mathrm{~cm}$ & End face diameter $1.41 \mathrm{~cm}$ & \\
$\mathrm{H}$ diameter $5.1 \mathrm{~cm}$ & Diameter $5.1 \mathrm{~cm}$ & Front face: $1 \times 1 \mathrm{~cm}^{2}$ & End face: $0.27 \times 0.27 \mathrm{~cm}^{2}$ \\
Small T & Taper angle $15.0^{\circ}$ & Front face: $2 \times 2 \mathrm{~cm}^{2}$ & End face: $1 \times 1 \mathrm{~cm}{ }^{2}$ \\
Large T & Taper angle $26.5^{\circ}$ & Length A: $3 \mathrm{~cm}$ & Length B: $4 \mathrm{~cm}$ \\
$120^{\circ} \mathrm{KW}$ & Cross section: $1 \times 1 \mathrm{~cm}^{2}$ & Length A: $4 \mathrm{~cm}$ & Length B: $4 \mathrm{~cm}$ \\
$90^{\circ} \mathrm{KW}$ & Cross section: $1 \times 1 \mathrm{~cm}^{2}$ & Length A: $2 \mathrm{~cm}$ & Length B: $4 \mathrm{~cm}$ \\
$60^{\circ} \mathrm{KW}$ & Cross section: $1 \times 1 \mathrm{~cm}^{2}$ & Length A: $4 \mathrm{~cm}$ & Length B: $4 \mathrm{~cm}$ \\
Double $90^{\circ} \mathrm{KW}$ & Cross section: $1 \times 1 \mathrm{~cm}^{2}$ & Length A: $1 \mathrm{~cm}$ & Length B: $1 \mathrm{~cm}$ \\
Thin $120^{\circ} \mathrm{KW}$ & Cross section: $0.5 \times 0.5 \mathrm{~cm}^{2}$ & & \\
\hline \hline
\end{tabular}

faces between the entrance and exit surfaces. Our model calculated the effects on each ray as it interacted with the surfaces many times, thereby providing an accurate simulation of light reflections in the actual link. For each link, the internal side of each surface was specified to be Schott BK7 glass, which has an index of refraction close to ZBLAN glass. In the case of a dielectric mirror, CODE $\mathrm{V}$ performed calculations of reflection and transmission according to a polynomial fit of the measured angle-dependent transmission and reflection coefficients of the actual mirrors. The CODE V Illumination Option was used to calculate the percentage of power transmitted from the entrance of the link to the exit surface. This option allowed a series of parallel planar sources to be arranged in the shape of a cube to approximate an isotropically emitting volume light source. When a ray was incident upon the final (image) surface, at the end of the link, it was terminated and its remaining power was recorded.

Table II provides a comparison between the CODE V optical modeling and the experimentally measured results. It is apparent that the computational results vary significantly from the measured results, especially for the hemisphere links. The measured and simulated results deviate by roughly a factor of three for the hemispheres, but the discrepancy for the dielectric mirror is only $60 \%$, and the small taper link is within $20 \%$ of performing as predicted. Nevertheless, the ranking of the models is the same for both simulation and measurement.

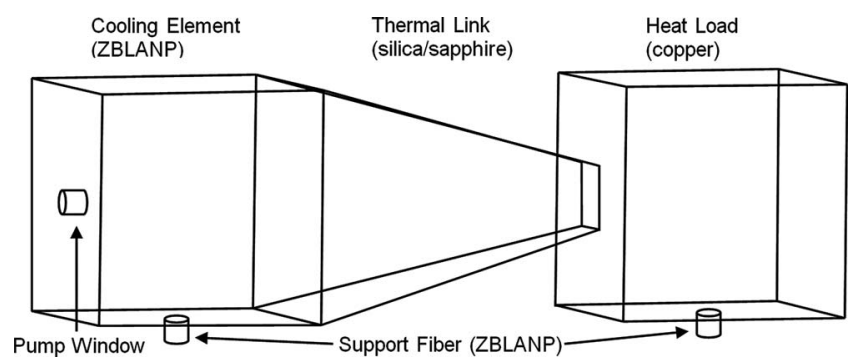

FIG. 9. Mechanical structure of LASSOR with a taper thermal link in COMsol. The cubic cooling element is at left, the cubic heat load is at right, and the thermal link is in the middle. There are small cylindrical support fibers at the bottom of both the cooling element and the heat load. The structure includes a small cylindrical hole in the trapping mirror where the pump laser enters the system.

\section{THERMAL MODELING OF LINKS}

We modeled the LASSOR system in COMSOL MULTIPHYSICS to solve the three-dimensional heat equation for a steady-state solution in a discretized mesh approximation of our system. The system's thermal behavior was evaluated using four thermal factors: the cooling power of the cooling element, blackbody radiation from the surrounding environment, conductive heat transfer through the fiber supports, and absorptive heating due to photons transmitted through the thermal link and absorbed at the heat load. Table III shows the dimensions of the links that were simulated in COMSOL, and Table IV shows the surface area of the link systems tested. Figure 9 shows an example of a thermal model of a system utilizing the small taper link.

The LASSOR model was composed of a $1 \mathrm{~cm}^{3}$ cooling element with a $1 \mathrm{~mm}$ diameter support fiber, a thermal link, and a $1 \mathrm{~cm}^{3}$ passive heat load. The support fiber was assigned the thermal properties (density, specific heat, and thermal conductivity) of ZBLANP, the thermal link was assigned the properties of silica, and the heat load was modeled as copper. As a result, the highly conductive heat load maintained a relatively constant temperature throughout its vol-

TABLE IV. Key link characteristics. The total surface area for the link designs and the optical transmission rates of the mirror-link system that were determined experimentally are shown: $\mathrm{KW}=$ kinked waveguide, $\mathrm{H}=$ hemisphere, and $\mathrm{T}=$ taper.

\begin{tabular}{lc}
\hline \hline Link type & $\begin{array}{c}\text { Total system surface area } \\
\left(\mathrm{cm}^{2}\right)\end{array}$ \\
\hline No link/load & 6.07 \\
Zero optical leakage & 10.07 \\
No link & 10.07 \\
$\mathrm{H}$ diameter $2.9 \mathrm{~cm}$ & 26.71 \\
$\mathrm{H}$ diameter $3.1 \mathrm{~cm}$ & 30.9 \\
$\mathrm{H}$ diameter $3.8 \mathrm{~cm}$ & 41.49 \\
$\mathrm{H}$ diameter $5.8 \mathrm{~cm}$ & 68.17 \\
Small T & 14.57 \\
Large T & 19.78 \\
$90^{\circ} \mathrm{KW}$ & 35.99 \\
$60^{\circ} \mathrm{KW}$ & 29.96 \\
$120^{\circ} \mathrm{KW}$ & 35.56 \\
Double $90^{\circ} \mathrm{KW}$ & 40.7 \\
\hline \hline
\end{tabular}




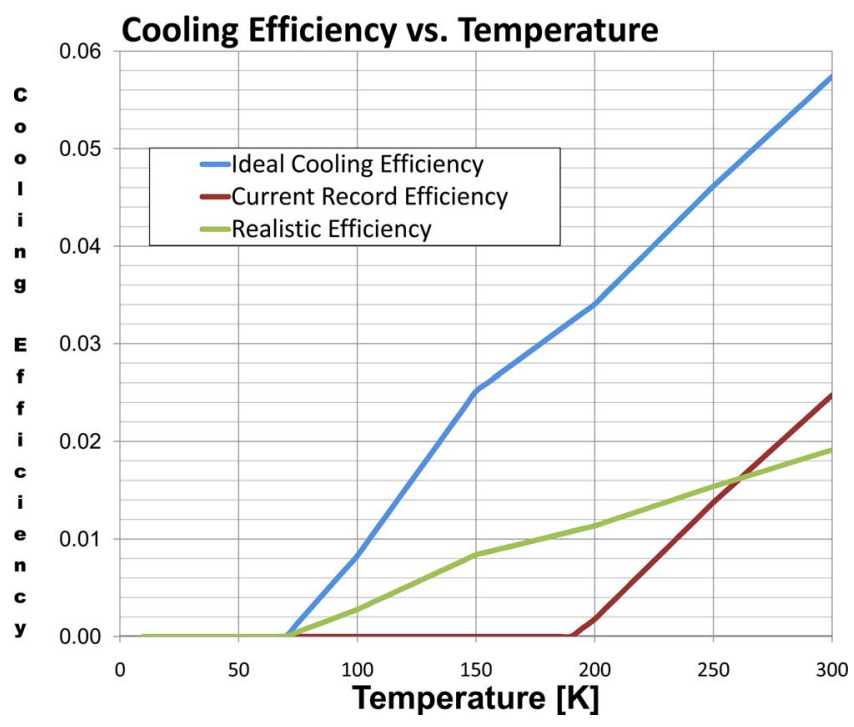

FIG. 10. (Color online) Cooling efficiency as a function of temperature within the cooling element. This figure shows the ideal, the current record, and the realistic cooling efficiencies attainable by the ZBLANP system as a function of temperature. The realistic efficiency used for thermal modeling corresponds to scaled values of the ideal efficiency such that the efficiency at $300 \mathrm{~K}$ is 0.02 . (Data supplied by the LASSOR team.)

ume when compared to the rest of the system. The thermal properties of silica glass were applied to most of the thermal links, while several models used sapphire to investigate the effects of a high thermal conductivity. In the model, the ideal cooling efficiency was scaled down by a factor of 3 to account for material imperfection in the cooling element. The temperature dependences of the ideal and experimentally measured cooling efficiencies are shown in Fig. 10. The scaled efficiency provides a conservative cooling estimate at room temperature, an increased sensitivity in the model to reabsorbed photons, and maintains the theoretical limit of nonzero efficiency above $77 \mathrm{~K}$.

We introduced a volumetric heating factor in the heat load to account for all of the optical leakage measured in each link design. The heating factor was calculated from the cuvette-to-load transmission of $1 / 6$ of the laser pump power. The 1/6 factor occurs because the fluorescent light in the cooling element is emitted isotropically over all six faces of the cube, therefore only $1 / 6$ of the pump laser power exits the face of the cube to which the mirror and link were attached. To model the radiative heat term, the chamber walls coated with a highly absorptive layer were set at $300 \mathrm{~K}$ and their emissivity at 0.1 . This means that the chamber walls emit $10 \%$ of the energy that a perfect blackbody radiates at 300 K. Furthermore the walls absorb $10 \%$ of the blackbody radiation from the system, while the other $90 \%$ is reflected back. This model assumes that the narrow band of fluorescence is completely absorbed by the chamber walls' highly absorptive coating. To be accurate in the model, one hole is placed in the chamber wall for a $1 \mathrm{~mm}$ diameter unityemissivity pump window as shown in Fig. 9 on the left end of the cooling element. The walls were positioned close to the surfaces of the system such that the total absorptive surface area of the system is nearly equal to the total radiative surface of the chamber. Closely spaced walls are optimal to reduce the total radiative load and to prevent light that leaves the system from re-entering.

The steady-state magnitudes of the four thermal factors are listed for each link design in Tables V and VI. The "no link/load" case was performed with only the cooling element to determine the minimum possible temperature a standalone cooling element could reach given our assumptions. The "zero optical leakage" case was performed by placing a heat load directly next to a cooling element and eliminating all optical transmission. This is an ideal control example, and as expected it achieved a lower temperature than any of the realistic thermal link models. The no link case was modeled similarly, but the optical transmission was set to $8.4 \%$, the

TABLE V. Magnitude of thermal factors and final steady state temperatures using a $5 \mathrm{~W}$ pump laser. Designs are sorted by the temperature reached at the heat load of the system, with the coolest designs listed first: $\mathrm{KW}=$ kinked waveguide, $\mathrm{H}=$ hemisphere, and $\mathrm{T}=$ taper.

\begin{tabular}{|c|c|c|c|c|c|c|c|}
\hline & $\begin{array}{l}\text { Cooling } \\
\text { power } \\
(\mathrm{mW})\end{array}$ & $\begin{array}{l}\text { Surface area } \\
\text { radiative load } \\
(\mathrm{mW})\end{array}$ & $\begin{array}{l}\text { Fluorescence } \\
\text { absorbed power } \\
\text { (mW) }\end{array}$ & $\begin{array}{l}\text { Conductive } \\
\text { power } \\
(\mathrm{mW})\end{array}$ & $\begin{array}{l}\text { Load } \\
\text { temperature } \\
(\mathrm{K})\end{array}$ & $\begin{array}{l}\text { Cooling element } \\
\text { temperature } \\
\text { (K) }\end{array}$ & $\begin{array}{c}\text { Temperature } \\
\text { difference } \\
(\mathrm{K})\end{array}$ \\
\hline No link/load & -61.5 & 22 & 0 & 39.7 & 205 & 205 & 0 \\
\hline Zero optical leakage & -77 & 29 & 0 & 52.6 & 249 & 246.6 & 2.4 \\
\hline Small $\mathrm{T}^{\mathrm{a}}$ & -79.5 & 35 & 0.3 & 47 & 255 & 252 & 3 \\
\hline Thin $120^{\circ} \mathrm{KW}^{\mathrm{a}}$ & -81.1 & 28.5 & 0.1 & 41.7 & 261 & 255 & 6 \\
\hline Small T & -77 & 34 & 0.3 & 45 & 262 & 256 & 6 \\
\hline Large $\mathrm{T}$ & -82 & 40.1 & 5 & 39 & 263 & 258 & 5 \\
\hline $\mathrm{H}$ diameter $2.9 \mathrm{~cm}$ & -83.9 & 45.7 & 1.1 & 35.7 & 267 & 261 & 6 \\
\hline $\mathrm{H}$ diameter $3.1 \mathrm{~cm}$ & -85 & 50 & 0.8 & 33 & 269 & 264 & 5 \\
\hline $120^{\circ} \mathrm{KW}^{\mathrm{a}}$ & -86 & 62 & 1 & 31 & 271 & 267 & 4 \\
\hline Double $90^{\circ} \mathrm{KW}^{\mathrm{a}}$ & -86 & 71 & 2.5 & 21 & 271 & 267 & 4 \\
\hline $60^{\circ} \mathrm{KW}^{\mathrm{a}}$ & -87.2 & 57.5 & 15 & 28.3 & 273 & 269 & 4 \\
\hline $\mathrm{H}$ diameter $3.8 \mathrm{~cm}$ & -87 & 56 & 0.6 & 28 & 274 & 268 & 6 \\
\hline $90^{\circ} \mathrm{KW}^{\mathrm{a}}$ & -88 & 57 & 9.9 & 28 & 274 & 270 & 4 \\
\hline $\mathrm{H}$ diameter $5.1 \mathrm{~cm}$ & -90 & 66 & 0.4 & 20 & 282 & 276 & 6 \\
\hline No Link & -93 & 9 & 71 & 13.6 & 288 & 283 & 5 \\
\hline
\end{tabular}

${ }^{\mathrm{a}} \mathrm{A}$ thermal conductivity of $41 \mathrm{~W} /(\mathrm{m} \mathrm{K})$ (i.e., sapphire) was used for these links, $1.38 \mathrm{~W} /(\mathrm{m} \mathrm{K})$ for the others. 
TABLE VI. Magnitude of thermal factors and final steady state temperatures using a $100 \mathrm{~W}$ pump laser. Designs are sorted by the temperature reached at the heat load of the system, with the coolest designs listed first: $\mathrm{KW}=$ kinked waveguide, $\mathrm{H}=$ hemisphere, and $\mathrm{T}=$ taper.

\begin{tabular}{|c|c|c|c|c|c|c|c|}
\hline & $\begin{array}{l}\text { Cooling } \\
\text { power } \\
(\mathrm{mW})\end{array}$ & $\begin{array}{l}\text { Surface area } \\
\text { radiative load } \\
(\mathrm{mW})\end{array}$ & $\begin{array}{c}\text { Fluorescence } \\
\text { absorbed power } \\
\text { (mW) }\end{array}$ & $\begin{array}{c}\text { Conductive } \\
\text { power } \\
(\mathrm{mW})\end{array}$ & $\begin{array}{l}\text { Load } \\
\text { temp. } \\
(\mathrm{K})\end{array}$ & $\begin{array}{l}\text { Cooling element } \\
\text { temp. } \\
\text { (K) }\end{array}$ & $\begin{array}{l}\text { Temp. } \\
\text { dif. } \\
(\mathrm{K})\end{array}$ \\
\hline No link/load & -119 & 28.4 & 0 & 91.4 & 83 & 83 & 0 \\
\hline No optical transmission & -250.7 & 62.6 & 0 & 204 & 102 & 94.8 & 7.2 \\
\hline Small $\mathrm{T}^{\mathrm{a}}$ & -274 & 83 & 6.9 & 201.2 & 107.2 & 96.7 & 10.5 \\
\hline Thin $120^{\circ} \mathrm{KW}^{\mathrm{a}}$ & -284 & 55 & 2.1 & 194.6 & 117 & 98 & 19 \\
\hline $\mathrm{H}$ diameter $2.9 \mathrm{~cm}$ & -332 & 117 & 21 & 191 & 120 & 101 & 19 \\
\hline $120^{\circ} \mathrm{KW}^{\mathrm{a}}$ & -370 & 210 & 19.7 & 193 & 120 & 104 & 16 \\
\hline Double $90^{\circ} \mathrm{KW}^{\mathrm{a}}$ & -360 & 231 & 51 & 127 & 122 & 103 & 19 \\
\hline $\mathrm{H}$ diameter $3.1 \mathrm{~cm}$ & -344 & 140 & 15 & 189 & 123 & 102 & 21 \\
\hline $\mathrm{H}$ diameter $3.8 \mathrm{~cm}$ & -381 & 182 & 12 & 184 & 129 & 105 & 24 \\
\hline Large $\mathrm{T}$ & -372 & 99 & 100 & 184 & 130 & 104 & 26 \\
\hline $\mathrm{H}$ diameter $5.1 \mathrm{~cm}$ & -460 & 296 & 8.3 & 154 & 143 & 111 & 32 \\
\hline $90^{\circ} \mathrm{KW}^{\mathrm{a}}$ & -526 & 201 & 197 & 172 & 145 & 117 & 28 \\
\hline Small T & -248 & 75 & 6.9 & 177 & 149 & 94 & 32 \\
\hline $60^{\circ} \mathrm{KW}^{\mathrm{a}}$ & -590 & 212 & 298 & 161 & 154 & 122 & 32 \\
\hline No link & -1467 & 12.5 & 1427 & 27 & 306 & 224 & 82 \\
\hline
\end{tabular}

${ }^{\mathrm{a}} \mathrm{A}$ thermal conductivity of $41 \mathrm{~W} /(\mathrm{m} \mathrm{K})$ (i.e., sapphire) was used for these links, $1.38 \mathrm{~W} /(\mathrm{m} \mathrm{K})$ for the others.

transmission rate of the trapping dielectric mirror. As expected, this control example performed worse than any model employing a physical thermal link.

The first heat source listed in Tables V and VI is the cooling power provided by the cooling element. The cooling power is determined using the power of the pump laser, the temperature that the cooling element reaches, and the efficiency of the cooling element at that temperature. Cooling power increased with pump laser power, while cooling efficiency decreased with cooling element temperature. The second source listed is the heating due to thermal radiation from the chamber walls. This heat load is calculated using the emissivity of the walls, the exposed surface area of the entire system (cooling element, link, and load), and the temperature difference between the walls (held at $300 \mathrm{~K}$ ) and the system's surfaces. This factor was larger in link designs with larger surface area and in designs that reached colder temperatures and therefore had larger temperature differences. The simulations showed that exposed surface area had a much larger impact on the radiative load than did the temperature difference. The third heat source is the heat generated in the system through optical absorption, which was calculated using the power of the pump laser used to cool the system and the optical transmission rate of the link; this was the dominant heat source without a thermal link and it was the focus of our link designs to diminish its effect. The final heat source is the power that conducts into the system through the support fibers. This factor is determined by the conductivity of the support fibers and the temperature difference between its two ends. Links that achieve lower temperatures have larger conductive loads. The difference in the conductive heat loads in links is due entirely to their steady-state temperatures. The temperature gradient for the taper link from the cooling element to the load is shown in Fig. 11.

\section{A. Results of thermal modeling}

The steady-state temperature convergence of the four thermal factors was calculated using COMSOL. Figures 12 and
13 show the relative magnitudes of the three heating terms graphically with pump laser powers of 5 and $100 \mathrm{~W}$, respectively. The cooling term is not shown because at steady state it is approximately the sum of the other three factors. Obviously in the no link case the (fluorescence) absorptive load dominates the system. In all other systems, the absorptive load is small compared to the (thermal) radiative and conductive loads. In the systems that achieved lower temperatures at the heat load, such as the small taper and the thin $120^{\circ}$ kinked waveguide, the absorptive load is negligible, and the conductive and radiative loads are approximately equal. In systems that achieved less cooling, even though there was good optical performance, the thermal behavior is dominated by large radiative loads due to their surface area. The large radiative loads prevented these systems from reaching lower temperatures.

Several of the designs, particularly the kinked waveguide designs, had very large temperature differences be-

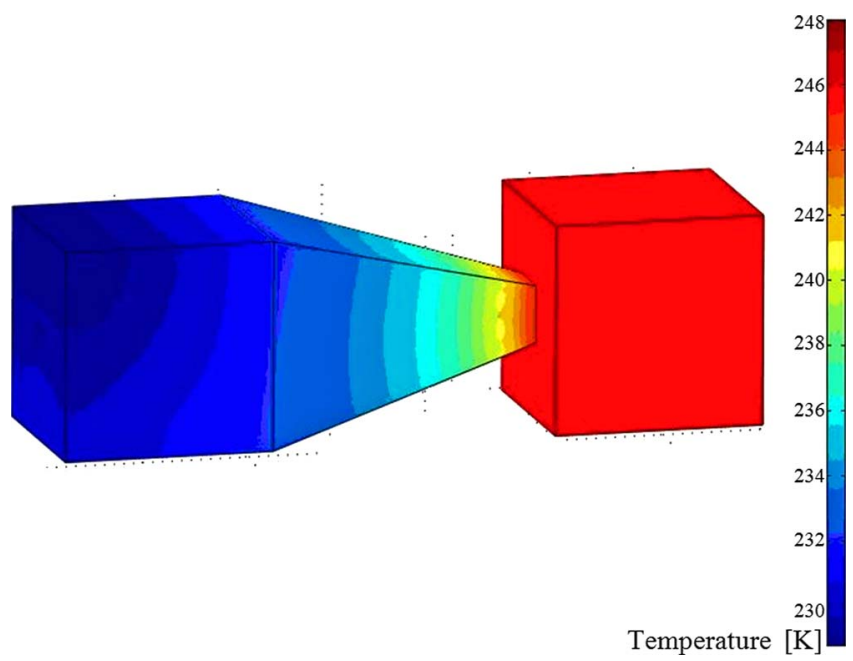

FIG. 11. (Color online) Temperature gradient over the small taper link. This figure shows the steady-state temperature visualization from the thermal modeling software. 


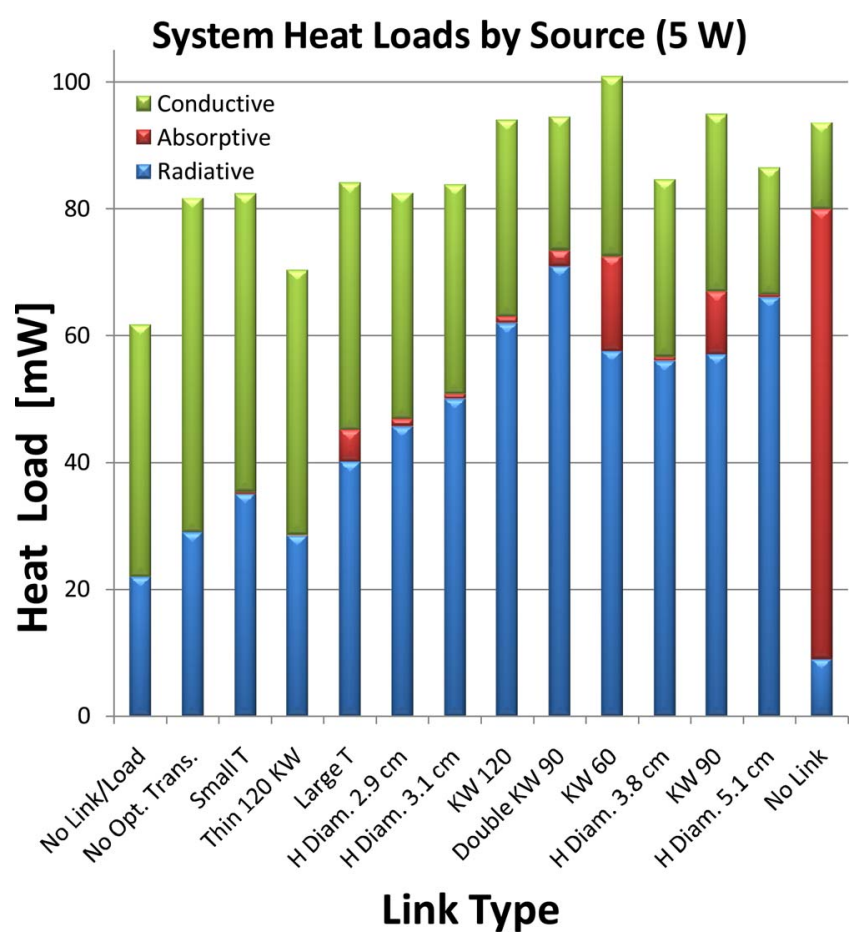

FIG. 12. (Color online) System heat loads using a $5 \mathrm{~W}$ laser pump power This figure shows the relative contribution of the three heating effects in the systems for a $5 \mathrm{~W}$ pumping laser power. Links are ordered from coolest steady-state temperature on the left to warmest on the right.

cause they had longer distances across which the heat must flow. In these designs the temperature differences were so large that these link designs were ruled out as feasible solutions. For example, the $90^{\circ}$ kinked waveguide had a temperature difference of $40 \mathrm{~K}$. The steady state temperatures achieved by the different links in the case of a 5 and $100 \mathrm{~W}$ pump laser are shown in Tables IV and V. The tables list the temperature reached at a point at the middle of the heat load and at the middle of the cooling element.

We investigated the effects of a higher conductivity link material by modeling the kinked waveguide and the small taper designs using sapphire. The high conductivity models with sapphire had a lower temperature difference between the cooling element and the load. However, since the physical links were constructed of acrylic, no experimental data were available on how these sapphire links would perform optically with an index of refraction of 1.8. Therefore, we used the optical transmission rate determined experimentally with an index of refraction of 1.5 (acrylic poly-methylmethacrylate (PMMA)) and changed only the thermal conductivity of the material in the thermal model.

Based on the final achievable temperature, the small taper design performed the best thermally. The thin $120^{\circ}$ kinked waveguide performed the best optically; however, it did not perform the best thermally. The cross-sectional area of the link was small, the distance through which heat must flow was large, and therefore the link was unable to effectively conduct heat from the heat load through the link to the cooling element. The small taper on the other hand had a comparatively large cross-sectional area and a small distance between the cooling element and the load. It was able to conduct thermal energy efficiently down the link.

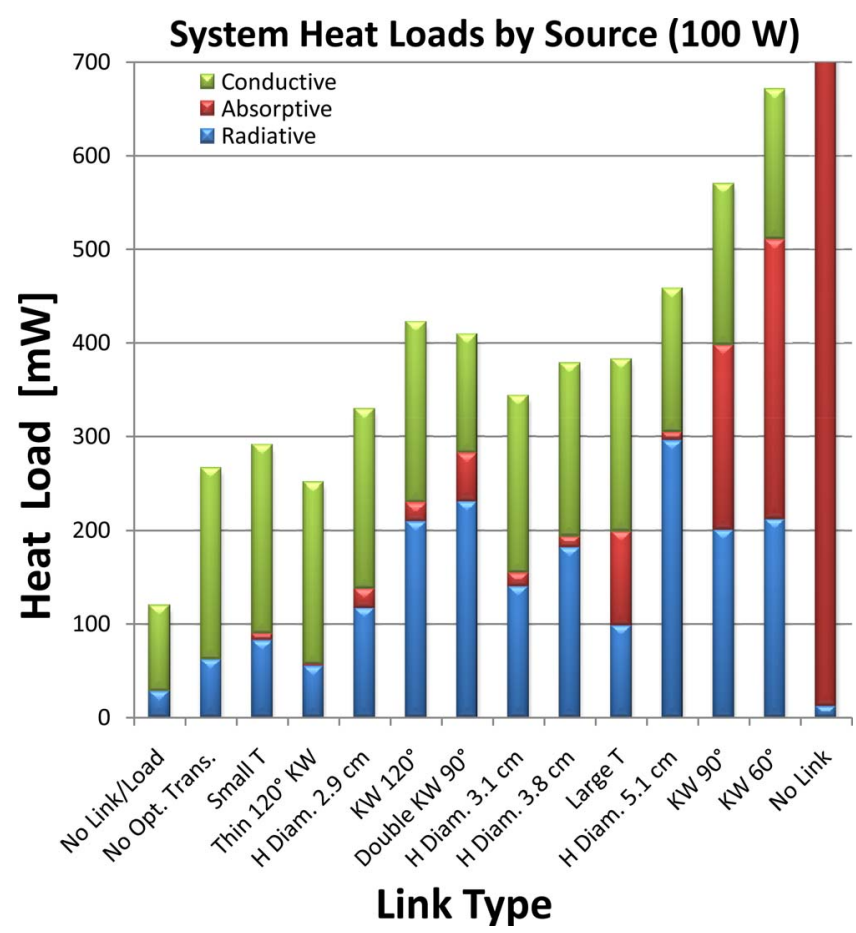

FIG. 13. (Color online) System heat loads using a $100 \mathrm{~W}$ laser pump power. Links are ordered from left to right with the coolest steady-state temperature on the left and the warmest on the right.

One way to reduce the radiative load is to lower the emissivity of the chamber walls. Lowering the emissivity will allow the links to reach a cooler temperature by decreasing the magnitude of the radiative load. As an example, reducing the emissivity of the walls from 0.1 to 0.02 reduced the radiative load on the small taper from 35 to $15 \mathrm{~mW}$, and the final temperature fell from 249 to $238.5 \mathrm{~K}$.

We find that by increasing the laser power, the final temperature the heat load can reach is substantially lower as listed in Table VI. The increased laser power increased the cooling power and increased the optical absorption due to more fluorescence photons propagating through the link. As the pump laser power input is increased from 5 to $100 \mathrm{~W}$, the relative magnitude of the absorptive load is increased proportionally, illustrated in Fig. 13. In the no link system, the increase in the absorptive load actually caused a net heating effect. In links such as the small taper design that performed well optically, even with a $100 \mathrm{~W}$ laser pumping power the optical absorption is still negligible compared to the other two heating effects. This implies that our links perform very well optically such that the fluorescence absorption heating term is no longer dominant. It is most important in future research to find ways to minimize the conductive and the radiative heat loads.

\section{CONCLUSIONS}

We have developed thermal links to couple an optical refrigerator to a heat load with minimal absorption of fluoresced photons. We have tested the effectiveness of these thermal links using a surrogate source to produce an angular distribution of visible light similar to the near-infrared fluorescence from the LASSOR system. The taper link design 
achieved the lowest photon transmission of $0.04 \%$ from the source and $0.5 \%$ from the trapping mirror, indicating a factor of 200 times reduction in light transmission over an optical refrigerator with no link. This decrease in light transmission improved the cooling by $26 \mathrm{~K}$ in the $5 \mathrm{~W}$ thermal model. As colder temperatures are achieved using thermal links, other heating mechanisms become significant such as black body radiation and conductive heat transfer through the supporting fibers.

It is clear from the thermal modeling performed on these links that the optical isolation is sufficiently high that heating from optical absorption is negligible compared to other thermal factors. Therefore, to further improve the cooling capabilities of optical refrigerators, we recommend reducing the heat that flows into the system through the support fibers, and the thermal radiation absorbed by the system from the chamber walls. To reduce conduction into the system, support fibers can be made with more insulating materials. To reduce the radiative load, the emissivity of the vacuum chamber walls can be lowered, or link designs which minimize exterior surface area can be chosen. One way to reduce both of these factors is to reduce the temperature of the chamber walls by using a multistage cooling system. Further technological improvements to dielectric mirror reflectivity at high angles of incidence can greatly enhance the performance of the optical cooler by reducing the size and corresponding surface area of the thermal link. We recommend using the optical refrigerator in microscale cooling applications as it will be least affected by the radiative load.

\section{ACKNOWLEDGMENTS}

This work was performed under a Harvey Mudd College joint Physics-Engineering Clinic project funded by Los Alamos National Laboratory. The authors would like to thank Markus Hehlen and the Los Alamos Solid State Optical Refrigerator team for their helpful insights during this project. The authors are also indebted to Cascade Optical Corporation for their assistance with the dielectric mirror coatings.

${ }^{1}$ M. Sheik-Bahae and R. Epstein, Nat. Photonics 1, 693 (2007).

${ }^{2}$ R. I. Epstein, M. I. Buchwald, B. C. Edwards, and T. R. Gosnell, Nature (London) 377, 500 (1995).

${ }^{3}$ B. Edwards, J. Anderson, R. Epstein, G. Mills, and A. Mord, J. Appl. Phys. 86, 6489 (1999)

${ }^{4}$ T. R. Gosnell, Opt. Lett. 24, 1041 (1999).

${ }^{5}$ J. Thiede, J. Distel, S. Greenfield, and R. Epstein, Appl. Phys. Lett. 86, 154107 (2005)

${ }^{6}$ P. Goldner and M. Mortier, J. Non-Cryst. Solids 284, 249 (2001).

${ }^{7}$ M. Hehlen, R. Epstein, and H. Inoue, Phys. Rev. B 75, 144302 (2007).

${ }^{8}$ B. Heeg, G. Rumbles, A. Khizhnyak, and P. A. Debarber, J. Appl. Phys. 91, 3356 (2002).

${ }^{9}$ B. Heeg, M. D. Stone, A. Khizhnyak, G. Rumbles, G. Mills, and P. A.
Debarber, Phys. Rev. A 70, 021401 (2004).

${ }^{10}$ D. Seletskiy, M. P. Hasselbeck, M. Sheik-Bahae, and R. I. Epstein, Proceedings of the Quantum Electronics and Laser Science Conference, Baltimore, MD, 2007 (unpublished)

${ }^{11}$ J. B. Khurgin, Proceedings of the SPIE Laser Cooling of Solids, San Jose, CA, 2007 (unpublished).

${ }^{12}$ J. B. Khurgin, Phys. Rev. Lett. 98, 177401 (2007).

${ }^{13}$ J. Fernandez, A. Mendioroz, A. J. Garcia, R. Balda, and J. L. Adam, Phys. Rev. B 62, 3213 (2000).

${ }^{14}$ S. R. Bowman and C. E. Mungan, Appl. Phys. B: Lasers Opt. B71, 807 (2000).

${ }^{15}$ C. E. Mungan, S. R. Bowman, and T. R. Gosnell, Proceedings of the International Conference on Lasers, Albuquerque, NM, 2000 (unpublished).

${ }^{16}$ R. Epstein, J. Brown, B. Edwards, and A. Gibbs, J. Appl. Phys. 90, 4815 (2001).

${ }^{17}$ S. Bigotta, D. Parisi, L. Bonelli, A. Toncelli, A. Di Lieto, and M. Tonelli, Opt. Mater. Opt. Mater. 28, 1321 (2006).

${ }^{18}$ A. Mendioroz, J. Fernandez, M. Voda, M. Al-Saleh, R. Balda, and A. J. Garcia-Adeva, Opt. Lett. 27, 1525 (2002).

${ }^{19}$ S. Bigotta, D. Parisi, L. Bonelli, A. Toncelli, M. Tonelli, and A. Di Lieto, J. Appl. Phys. 100, 013109 (2006).

${ }^{20}$ C. W. Hoyt, M. Sheik-Bahae, R. I. Epstein, B. C. Edwards, and J. E. Anderson, Phys. Rev. Lett. 85, 3600 (2000).

${ }^{21}$ C. W. Hoyt, M. P. Hasselbeck, M. Sheik-Bahae, R. I. Epstein, S. Greenfield, J. Thiede, J. Distel, and J. Valencia, J. Opt. Soc. Am. B 20, 1066 (2003).

${ }^{22}$ W. Patterson, S. Bigotta, M. Sheik-Bahae, D. Parisi, M. Tonelli, and R. Epstein, Opt. Express 16, 1704 (2008).

${ }^{23}$ J. Fernandez, A. J. Garcia-Adeva, and R. Balda, Phys. Rev. Lett. 97, 033001 (2006)

${ }^{24}$ J. B. Khurgin, Proceedings of the SPIE Physics and Simulation of Optoelectronic Devices XIV, San Jose, CA, 2006 (unpublished).

${ }^{25}$ D. Kai and Z. Yi-Ping, Chin. Phys. Lett. 25, 1878 (2008).

${ }^{26}$ M. Sheik-Bahae and R. I. Epstein, Phys. Rev. Lett. 92, 247403 (2004)

${ }^{27}$ M. Sheik-Bahae, B. Imangholi, M. P. Hasselbeck, R. I. Epstein, and S. Kurtz, Proceedings of the SPIE Physics and Simulation of Optoelectronic Devices XIV, San Jose, CA, 2006 (unpublished).

${ }^{28}$ J. Li, Phys. Rev. B 75, 155315 (2007).

${ }^{29}$ G. Mills, J. Turner-Valle, and M. Buchwald, Proceedings of the AIP CEC Conference, Anchorage, AK, 2003 (unpublished).

${ }^{30}$ G. Mills, W. S. Good, and A. J. Mord, Proceedings of the NASA ESTO Conference, Palo Alto, CA, 2004 (unpublished).

${ }^{31}$ G. Mills and A. J. Mord, Proceedings of the NASA ESTO Conference, College Park, MD, 2005 (unpublished).

${ }^{32}$ X. L. Ruan and M. Kaviany, J. Heat Transfer 129, 3 (2007).

${ }^{33}$ C. Mungan, M. Buchwald, B. Edwards, and R. Epstein, Phys. Rev. Lett. 78, 1030 (1997)

${ }^{34}$ G. Mills, J. Fleming, Z. Wei, and J. Turner-Valle, Proceedings of the NASA ESTO Conference, Pasadena, CA, 2002 (unpublished).

${ }^{35}$ J. Parker, D. Mar, S. Von der Porten, J. Hankinson, K. Byram, C. Lee, K. Mayeda, R. Haskell, Q. Yang, S. Greenfield, and R. I. Epstein, Proceedings of the SPIE Photonics West Conference, San Jose, CA, 2008 (unpublished).

${ }^{36}$ K. Byram, D. Mar, J. Parker, S. Von der Porten, J. Hankinson, C. Lee, K. Mayeda, R. C. Haskell, Q. Yang, S. R. Greenfield, and R. I. Epstein, Proceedings of the SPIE Photonics West Conference, San Jose, CA, 2008 (unpublished).

${ }^{37}$ H. Gauck, T. H. Gfroerer, M. J. Renn, E. A. Cornell, and K. A. Bertness, Appl. Phys. A: Mater. Sci. Process. 64, 143 (1997).

${ }^{38}$ Philips Lumileds Lighting Company, Technical Data Sheet DS46, http:// www.lumileds.com/pdfs/DS46.pdf. 